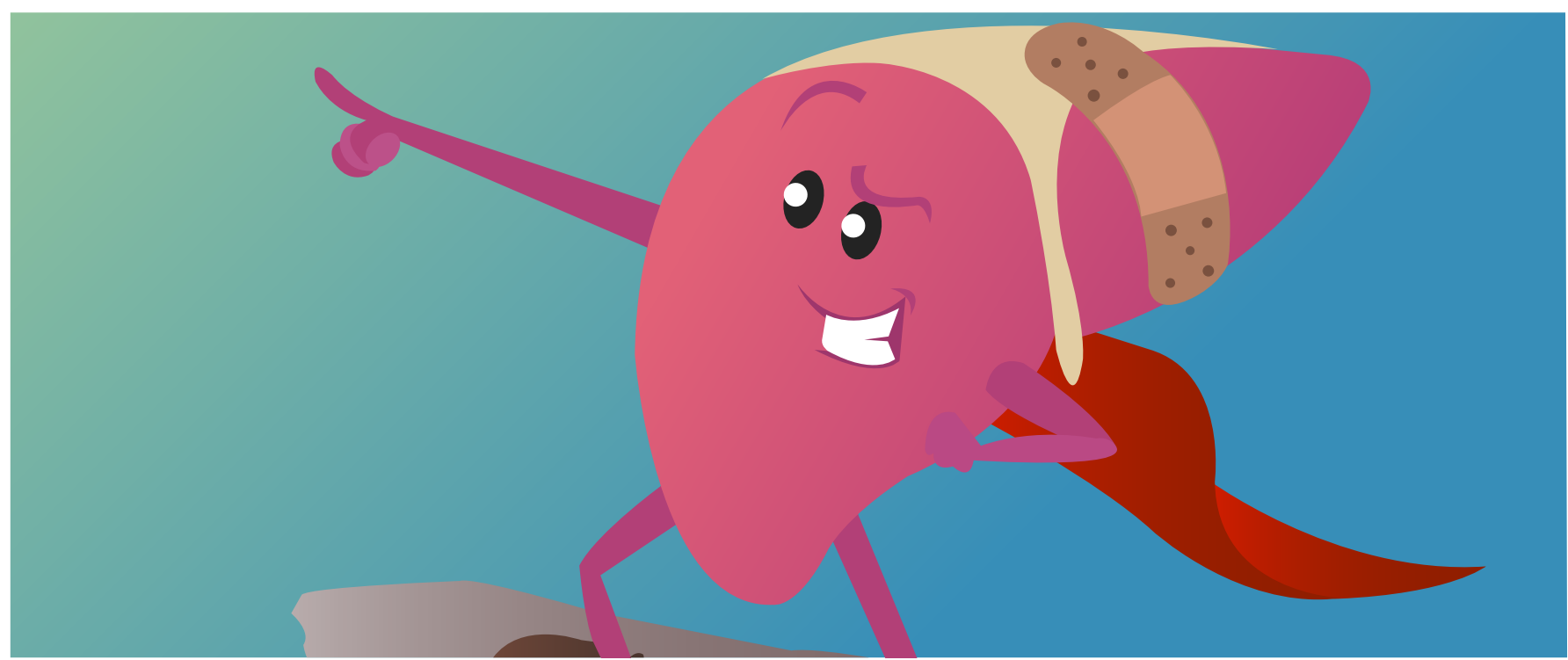

\title{
WHY IS THE LIVER SO AMAZING?
}

\section{Blanca Delgado-Coello*}

Department of Biochemistry and Structural Biology, Instituto de Fisiología Celular, Universidad Nacional Autónoma de México, Mexico City, Mexico

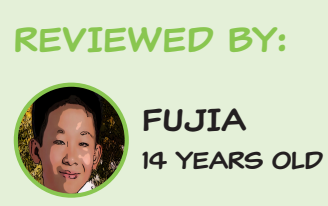

The liver is an organ that performs a lot of important functions in the body. However, if you observe it under the microscope, it seems to be very quiet because most of its cells remain in a non-dividing state (this is called quiescent). The liver is so important that it is provided with a great ability to tolerate several kinds of injuries. After a wound or other damage, all the cells in the liver change and divide until the normal size of the liver is restored. This interesting process is commonly known as "liver regeneration." If the injury to the liver is so serious that the liver cannot regenerate, a person may need a new liver, that is, a transplant. Right now, more than 15,000 people in the USA are waiting for liver transplants. You will learn that, due to its ability to "regenerate," the liver can be donated while the donor is still alive.

\section{STRUCTURE AND FUNCTIONS OF THE LIVER}

The liver is the largest organ located in the abdomen; it weighs around $1.5 \mathrm{~kg}$ in humans and is organized in sections called lobes [1]. The liver is like a big factory, where some molecules are produced and others are destroyed in order to get the energy the body needs to work. The liver can store energy and use it during long fasting periods or when we sleep. The liver can dispose of toxic 


\section{DETOXIFICATION}

Processing of toxic substances to remove them from the body.

\section{BILIARY TREE}

Set of vessels where bile travels from the liver to the gallbladder.

\section{FIGURE 1}

The structure of the liver. A. The liver is the largest organ located in the abdomen, in green it is indicated the system of vessels (biliary tree) where bile goes from the liver to the gallbladder, then bile reaches the small intestine where nutrients are taken up. B. If we observe a liver slice under a microscope, we can see rows of the most abundant and largest cells, the hepatocytes. Note that each hepatocyte has small channels where the bile passes through on its way out of the liver to the gallbladder and small intestine. Other important cells are the Kupffer cells that perform defense functions and are located in the spaces between rows of hepatocytes, which are lined by a layer of sinusoidal endothelial cells. The hepatic stellate cells are located in the narrow space between the hepatocytes and the sinusoidal endothelial cells. Red blood cells are also shown between the layers of hepatocytes. substances in the body, like alcohol, medicines, or drugs, through the production of a substance called bile (this process is called detoxification). Bile is a kind of juice that acts as a detergent to break down certain substances and to digest fats. Because it is impossible to mix water and oil, the liver uses bile to catch drops of fat in a "bubble." The structure of the bubbles allows them to travel through the watery environment of the body. After being produced by the liver, bile is transported through small vessels (bile canaliculi) located in the hepatocytes to a nearby organ called the gallbladder, then to the intestine where nutrients are recovered, and then, it goes back to the liver. The route bile follows from the liver to the intestine is known as the biliary tree. In addition, the liver acts as part of the immune system, as it helps the body to fight against infectious organisms. To perform all of these complex tasks, the liver needs to contain several types of cells (Figure 1). At first glance, the liver has a deep red color. That is because it contains plenty of blood vessels or sinusoids transporting blood from the intestines, the spleen, and the pancreas. The most abundant and largest cells of the liver are the hepatocytes, which are the cells that produce and destroy certain molecules to give the body energy. Other cells help the liver to work. Kupffer cells are the "guardian" cells of the liver that eat foreign bacteria. The star-shaped hepatic stellate cells store vitamin A, which looks like bright drops inside of these cells. Hepatic stellate cells also help to produce the proteins that make up the structure of the liver. The sinusoidal endothelial cells cover the abundant blood vessels of the liver.

At this point, I hope you realize that the liver is an essential organ; no one can survive without it. The liver has interesting mechanisms to protect itself from different injuries and diseases.

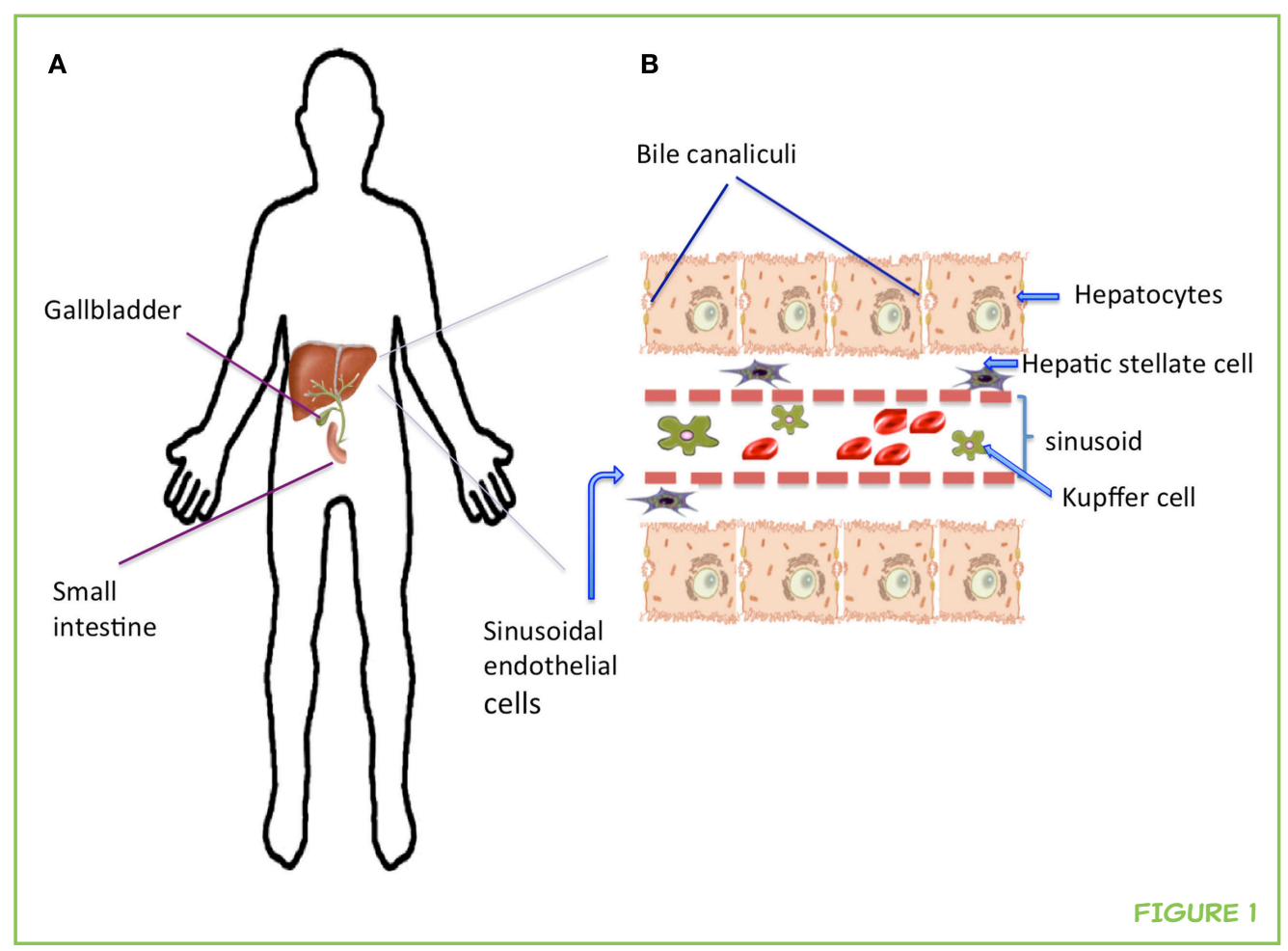


QUIESCENT

Stage where cells are not dividing.
COMPENSATORY HYPERPLASIA

Process by which the liver after being damaged, restore its size increasing the number of liver cells.

\section{WHAT IS LIVER REGENERATION?}

Under normal conditions, we say that the liver is a quiescent organ. This means that if you observe it under a microscope, you can find only one cell dividing among thousands of cells! However, if the liver is physical damaged (for example, a wound) or chemically damaged (by drugs or alcohol), its cells are pushed to divide and grow. This phenomenon is known as liver regeneration and it is even mentioned in Greek mythology. The most popular myth that refers to this phenomenon is that of Prometheus, who stole fire. His punishment was to stay chained in the Caucasus Mountains where an eagle fed on his liver every day.

Although people have known about liver regeneration for a long time, it was not until the 1900s that liver regeneration was formally studied and discovered to occur in all mammals. To study liver regeneration, in 1931, Higgins and Anderson performed an experiment in rats, in which the two largest lobes of the liver were very carefully removed [2]. Work with animals involves the use of clean instruments, anesthesia, and respectful treatment. Because the liver has a lot of blood vessels, to avoid bleeding, the main vessels of the liver were tied with a special thread. Higgins and Anderson found that the rat liver returned to its normal size in 7 days. Even today, this is still the most popular way for scientists to study liver regeneration. Using experiments of this type, we are able to understand what kind of genes, hormones, and growth factor proteins participate in the process of liver regeneration.

Even though we have been calling the re-growth of the liver "liver regeneration," that is not really an accurate description of what happens. The term "regeneration" actually describes the process by which animals can replace an entire part of the body. For example, if a lizard loses its tail while it escaping from a predator, its tail can eventually grow back. This cannot happen with the liver-if someone were to lose their entire liver, he or she could not just grow a new one. So, even though we will continue to call it "liver regeneration," the more accurate term for what happens in the liver is compensatory hyperplasia [3]. Although this term may sound complicated, it actually means an increase in the size of the liver caused by an increase in the number of cells. To be able to divide, the liver cells need to "wake up" or as scientists say, the cells need to become "activated." The process of liver regeneration happens in three phases (Figure 2). During the three phases, all the cells work as a team and communicate with each other. This communication is what tells the liver cells to come out of quiescence and begin dividing. Minutes after the liver detects damage, genes in the nuclei of the liver cells send signals to prepare the cells for division. This is called the initiation phase. During the proliferation phase, the liver cells divide. Cell division continues until the liver recovers its original size, then the termination phase is reached, and the liver cells stop dividing. While all this is happening, the liver still needs to perform all its normal functions, to keep the animal alive and healthy. 


\section{FIGURE 2}

Phases of the liver regeneration process.

A. Liver cells are normally quiescent, meaning they are not dividing, but after an injury they become activated and liver regeneration starts. The process of regeneration happens in three phases: initiation, proliferation, and termination. B. During the initiation phase, the cells start to change and remember that there is constant communication among different cell types during the whole process. C. During the proliferation phase, the DNA is replicated and more proteins are produced; then, the liver cells divide. D. When the liver is close to its initial size, stop signals occur that mark the termination phase, and the cells stop dividing.

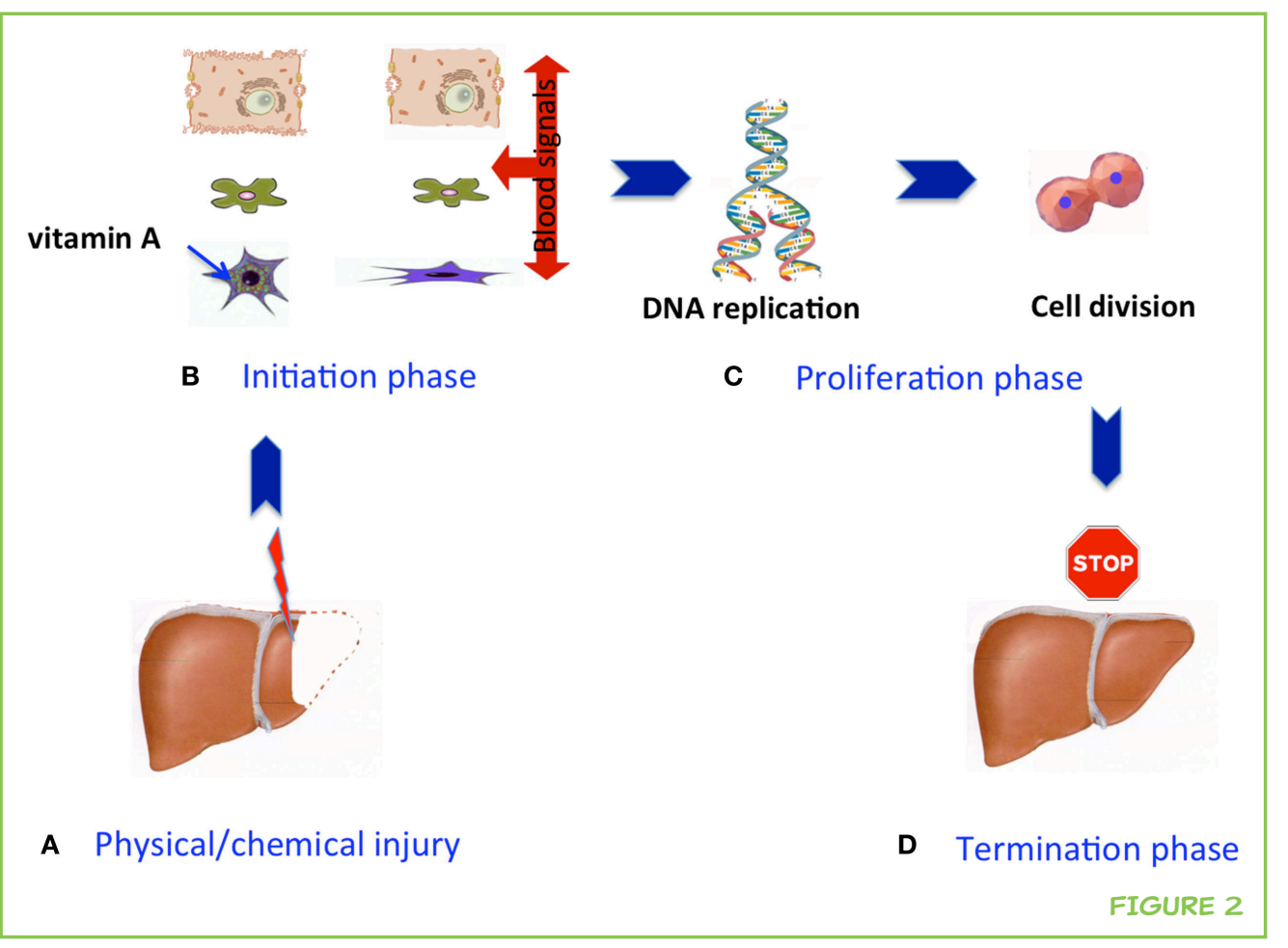

How does the liver know when to stop growing? This is an important question, and we can say that the size of the liver is a very important factor. The liver represents around 3\% of the body, and this proportion tends to stay constant, regardless of the size of the body. If you want to know your liver's size, just multiply your weight by 0.03 ! The same proportion applies in other mammals. So, if a small dog receives a big dog's liver, the liver will grow according to the small one's body size. Some scientists have given the name "hepatostat" (like "thermostat," only "hepato" means liver) to the system that regulates the liver's size. In general, we can imagine that the hepatostat contains a set of proteins that send stop signals to the liver, so that it will no longer grow. Note that these "stop" proteins have the opposite effects of those acting at the initiation phase (those that giver the order to "divide"). Scientists still need to do more work to understand how the hepatostat is controlled and the factors that affect it.

\section{WHY IS KNOWLEDGE ABOUT LIVER REGENERATION USEFUL?}

A lot of the knowledge produced by scientists can be used to solve specific problems in the short or long term. Because liver regeneration involves wellcontrolled growth, we can use our knowledge of liver regeneration to help us understand other types of growth, such the uncontrolled growth that occurs in cancer cells.

Doctors may be able to use knowledge about liver regeneration to help people who have diseases or liver injury that push the liver beyond its ability 
DECELLULARIZATION

Process performed to remove the cells of a tissue/organ to conserve the matrix that can be refilled with healthy cells.

\section{FIGURE 3}

How the rat liver looks before $\mathbf{A}$. and after $\mathbf{B}$. being "cleaned" or having all the cells removed. Image of decellularized liver courtesy of Dr. Alejandro Soto-Gutierrez. to regenerate. In extreme cases, these people may need a liver transplant. Complete livers or parts of a liver can be obtained from dead donors and transplanted into patients. But, now that you know about the regenerative ability of the liver, you can understand why it is also possible for a healthy, living person to donate a piece of his or her liver to someone who needs a transplant. The donor's liver will grow back! Even though this type of transplant from a live donor is possible, there are not enough donors to handle the high number of people who need liver transplants. Right now, in the USA, almost 15,000 people need new livers [4].

Also, scientists are working to design devices to help patients with certain liver problems. These devices can temporarily help patients while they wait for a transplant, in a similar way to the dialysis machines that are used to help patients with kidney failure [5]. Tissue engineering is a branch of science that might also help patients who are waiting for a transplant. Tissue engineering uses special methods and materials to try to grow livers in the lab. In the absence of donors, these lab-grown livers may be transplanted into the patients to improve or replace their damaged liver tissues.

A huge part of the knowledge of the biological behavior of liver cells has been obtained studying the liver regeneration phenomenon. Taking into consideration that knowledge, and the fact that liver donors are scarce, another strategy of the tissue engineering is to "recycle" the whole liver or a small part. The liver of a dead donor can be used, but all the original cells are removed by running a special solution through the liver's vessels, until it looks totally transparent (Figure 3). This process is called decellularization, and it is done because the three dimensional structure or matrix that supports the cellular components of the liver is well-kept. Observe in the picture the well-preserved blood vessels of the liver matrix. In this way, the clean liver can receive new hepatic cells from healthy people or animals and then be transplanted [6]. This process has been done successfully in several mammalian species, but it is difficult. Cleaning a rat liver can take $48 \mathrm{~h}$, and cleaning a complete

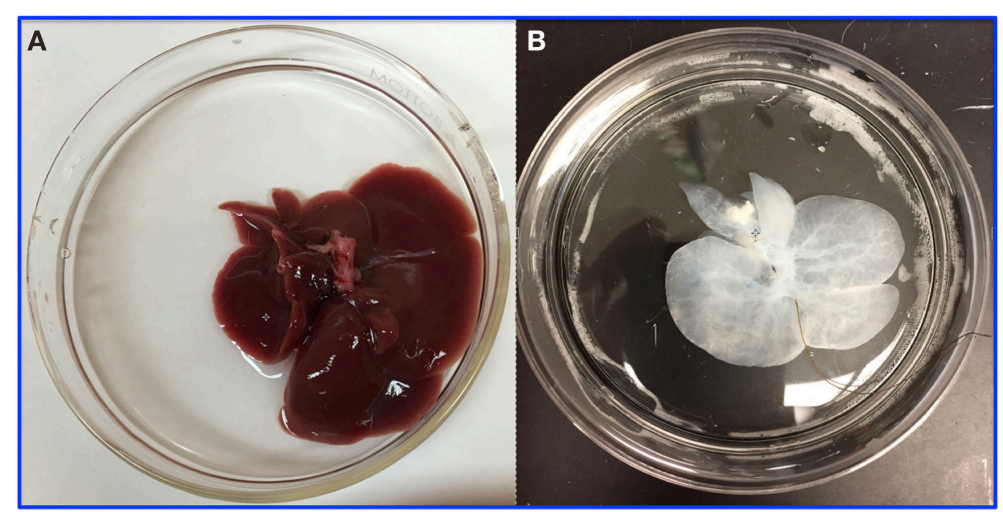

FIGURE 3 
human liver can take up to 6 weeks! However, a problem to solve after the decellularization is getting enough healthy liver cells to refill the clean liver. Today, an alternative under study is the production of liver cells from stem cells located in or out of the liver. But that is another story.

\section{CONCLUSION}

The goal of writing this article was to inform young people about how the liver works in the body and to describe its amazing capacity to respond to different injuries. Another goal was to provide knowledge about scientific research that is focused on improving the quality of life of people who have severe liver diseases. With this information, I hope you understand the critical role your liver plays in your body's health, and the importance of taking care of your liver over your whole lifetime.

\section{ACKNOWLEDGMENTS}

The author would like to thank Dr. Alejandro Soto-Gutierrez, who works at the University of Pittsburgh, PA, USA, for sharing a photo of a decellularized liver, and Mr. Patrick Weill, who assisted with English language editing.

\section{REFERENCES}

1. Tsung, A., and Geller, D. A. 2011. Gross and cellular anatomy of the liver. In Molecular Pathology of Liver Diseases. ed. S. P. S. Monga. Pittsburgh, PA: Springer Science + Business Media, LLC. p. 3-6.

2. Higgins, G. M., and Anderson, R. M. 1931. Experimental pathology of the liver. I. Restoration of the liver of the white rat following partial surgical removal. Arch. Pathol. 12:186-202.

3. Columbano, A., and Shinosuka, H. 1996. Liver regeneration versus direct hyperplasia. FASEB J. 10:1118-28.

4. Website of the U.S. Department of Health and Human Services. Organ Procurement and Transplantation Network (OPTN-HRSA). Available from: http://optn.transplant. hrsa.gov (accessed March 14, 2017).

5. Lee, S. Y., Kim, H. J., and Choi, D. 2015. Cell sources, liver support systems and liver tissue engineering: alternatives to liver transplantation. Int. J. Stem Cells 8:36-47. doi:10.15283/ijsc.2015.8.1.36

6. Uygun, B. E., Soto-Gutierrez, A., Yagi, H., Izamis, M. L., Guzzardi, M. A., Shulman, C., et al. 2010. Organ reengineering through development of a transplantable recellularized liver graft using decellularized liver matrix. Nat. Med. 16:814-20. doi:10.1038/nm.2170

SUBMITTED: 04 April 2017; ACCEPTED: 30 June 2017;

PUBLISHED ONLINE: 24 July 2017.

EDITED BY: Fulvio D’Acquisto, Queen Mary University of London, United Kingdom 
CITATION: Delgado-Coello B (2017) Why Is the Liver So Amazing? Front. Young Minds 5:38. doi:10.3389/frym.2017.00038

CONFLICT OF INTEREST STATEMENT: The author declares that the research was conducted in the absence of any commercial or financial relationships that could be construed as a potential conflict of interest.

COPYRIGHT @ 2017 Delgado-Coello. This is an open-access article distributed under the terms of the Creative Commons Attribution License (CC BY). The use, distribution or reproduction in other forums is permitted, provided the original author(s) or licensor are credited and that the original publication in this journal is cited, in accordance with accepted academic practice. No use, distribution or reproduction is permitted which does not comply with these terms.

\section{REVIEWED BY}

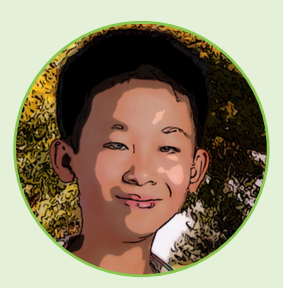

\section{FUJIA, 14 YEARS OLD}

He eats, he drinks, he sleeps, he is Fujia! Your average high schooler whose talents include science, sarcasm, writing, math, and sarcasm. In his free time, Fujia enjoys playing tennis, video games, writing in third person, and sitting in a dark room contemplating life choices. On rainy days he can often be found on his computer doing things, on sunny days he can often be found on his computer doing things, his computer is basically attached to him at this point.

\section{AUTHOR}

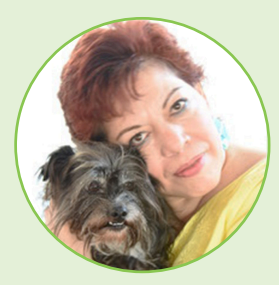

\section{BLANCA DELGADO-COELLO}

I am a cellular biologist who has worked in the field for more than 25 years; first, studying the nervous system and then understanding calcium regulation in several tissues, especially in the liver. After so many years, the liver never ceases to amaze me! Also, I am interested in communicating ideas/topics of scientific interest or that lead to personal reflection. In this case, the motivation is to teach young people about the liver regeneration process and its relevance from medical and social point of view. I loved discovering this journal! *bdelgado@ifc.unam.mx 